OPEN ACCESS

Edited by:

Mike Z. Yao,

University of Illinois at Urbana-

Champaign, United States

Reviewed by:

Jung-Seok Choi,

Seoul Metropolitan Government Seoul National University Boramae

Medical Center, South Korea

Mei Yang,

Shenzhen Mental Health Centre, China

*Correspondence:

$\mathrm{Li} \mathrm{Li}$

janetlee2007@126.com

Mark D. Griffiths

mark.griffiths@ntu.ac.uk

Specialty section:

This article was submitted to

Addictive Disorders,

a section of the journal

Frontiers in Psychiatry

Received: 25 June 2020 Accepted: 11 August 2020

Published: 27 August 2020

Citation:

Li L, Griffiths MD, Mei S and Niu Z (2020) Fear of Missing Out and Smartphone Addiction Mediates the

Relationship Between Positive and

Negative Affect and Sleep Quality Among Chinese University Students.

Front. Psychiatry 11:877.

doi: 10.3389/fpsyt.2020.00877

\section{Fear of Missing Out and Smartphone Addiction Mediates the Relationship Between Positive and Negative Affect and Sleep Quality Among Chinese University Students}

\author{
$\mathrm{Li} \mathrm{Li}^{1 *}$, Mark D. Griffiths ${ }^{2 *}$, Songli Mei ${ }^{3}$ and Zhimin Niu ${ }^{1}$
}

${ }^{1}$ School of Humanities and Social Sciences, Gannan Medical University, Ganzhou, China, ${ }^{2}$ International Gaming Research Unit, Nottingham Trent University, Nottingham, United Kingdom, ${ }^{3}$ School of Public Health, Jilin University, Changchun, China

Background and Aims: The widespread use of social media on smartphones has lead to the fear of missing out (FoMO) and smartphone addiction among a minority of adolescents and adults. However, few studies have investigated the impact of trait affect on sleep quality via FoMO and smartphone addiction. The present study examined whether FoMO (trait-FoMO and state-FoMO) and smartphone addiction mediated the relationship between positive affect (PA)/negative affect (NA) and sleep quality, and the prevalence of sleep disturbance among Chinese university students.

Methods: The sample comprised 1,164 university students and they completed a survey which included the Chinese Trait-State Fear of Missing Out Scale (T-SFoMOS-C), Mobile Phone Addiction Index (MPAl), International Positive and Negative Affect Scale ShortForm (I-PANAS-SF), and the Pittsburgh Sleep Quality Index (PSQI).

Results: The prevalence of sleep disturbance was found to be $15.98 \%$ among Chinese university students. The serial multiple mediation effects indicated that PA directly impacted on sleep quality, but the mediation effects of trait-FoMO and state-FoMO were not found. NA impacted on sleep quality via the mediation effects of trait-FoMO/ state-FoMO and smartphone addiction.

Conclusion: Negative affect was positively associated with poor sleep quality, which was partially mediated by FoMO and smartphone addiction among Chinese university students. Individuals with high negative affect were more likely to have high levels of FoMO and were more prone to smartphone addiction as well as experiencing poor sleep quality. These findings provide an evidence base for emotion management, prevention of smartphone addiction, and sleep improvement.

Keywords: trait-fear of missing out, state-fear of missing out, smartphone addiction, sleep quality, positive affect, negative affect 


\section{INTRODUCTION}

The phenomenon of 'fear of missing out' (FoMO) has become more prevalent due to social media use over past few years $(1,2)$. A survey from Xinli001 (i.e., a professional psychological information and service platform in China) reported that $15.2 \%$ of respondents experienced severe FoMO (3). As “a pervasive apprehension that others might be having rewarding experiences from which one is absent" (1), FoMO is also considered as a two-dimensional construct including traitFoMO (i.e., "a relatively stable individual characteristic") and state-FoMO (i.e., "fear of missing out online content and interaction with others using social media") (4).

Recent studies have identified that social media use (5-9), psychological need satisfaction $(1,10-12)$, and personality traits (13-17) may be considered as risk factors of FoMO. Wolniewicz et al. also reported that FoMO was most strongly associated with both problematic smartphone use and normal smartphone use (e.g., video and voice calls, text/instant messaging, email, social networking sites) relative to negative affect and fears of negative and positive evaluation (18), similar to the relationship between FoMO and other types of internet addiction (e.g., Facebook addiction, social networking site [SNS] addiction) (19-23). StateFoMO has been found to directly and indirectly impact phubbing via problematic Instagram use, whereas trait-FoMO has been indirectly associated with phubbing via state-FoMO and problematic Instagram use (24). Additionally, some studies have shown the associations between high levels of FoMO and negative outcomes, such as bad school performance, fatigue, and decreased sleep (25-28).

In March 2020, the China Internet Network Information Centre reported that the total number of Chinese internet users was 904 million, with 897 million accessing the internet via smartphones (99.3\%) (29). Smartphone addiction has been found to be prevalent among adolescents and emerging adults in China and elsewhere in the world (30-32). The prevalence of problematic smartphone use/smartphone addiction was estimated in one study to be $21.3 \%$ among Chinese undergraduates (33).

As a form of technological addiction or one of generalized internet addictions (34-37), smartphone addiction is also described as "an inability by individuals to regulate their use of smartphones and which eventually leads to negative consequences and clinical impairment in daily life" (38). Some risk factors of smartphone addiction have been examined such as negative affect (e.g., depression, anxiety and loneliness), low Internet selfefficacy, high impulsivity, as well as narcissism (39-45). In studies of smartphone addiction, Additionally, smartphone addiction has shown demonstrable association with alcohol use disorder symptoms, specific mental health diagnoses (i.e., ADHD, anxiety, depression, and PTSD), poor scholastic performance (46), vision problems (47), driving risk (48), and musculoskeletal pain (49-52). Smartphone addiction is also associated with poor sleep quality $(32,53,54)$. Most studies have also shown that smartphone addiction is often associated with social media addiction because social media use is primarily engaged in via smartphones $(55,56)$.
Negative urgency has been shown to mediate the relationship between negative emotion and smartphone addiction (57). Moreover, smartphone addiction may serve as a mediator between loneliness and sleep quality (30).

Trait affect as a key personality construct has been an important concept in applied psychology (58). The positive and negative dimensions of trait affect have been defined by several scholars $(59,60)$. Positive affect (PA) reflects "the extent to which a person feels enthusiastic, active, and alert", whereas negative affect (NA) is "a general dimension of subjective distress and unpleasurable engagement that subsumes a variety of aversive mood states, including anger, contempt, disgust, guilt, fear, and nervousness" (61).

Positive affect and negative affect as ambivalent emotions have been found to be associated with high levels of FoMO when using Facebook (1). Przybylski et al. developed the Fear of Missing Out Scale (FoMOS), which is a unidimensional scale for assessing trait FoMO. Individuals experiencing lower levels of general mood reported higher levels of FoMO (1). Moreover, FoMO has been found to mediate the relationship between general mood and social media engagement, as well as basic need satisfaction/life satisfaction and social media engagement (1). Riordan et al. reported that negative affect has been associated with FoMO when using Facebook (62). Shin et al. also reported the mediating effects of affect on the associations between personality factors and internet gaming disorder (63). In addition, envy as a specific negative affect has been shown to impact on problematic smartphone use and SNS addiction via FoMO $(64,65)$. In the interaction of Person-Affect-CognitionExecution (I-PACE) model, Brand et al. proposed that internetrelated disorders (e.g., smartphone addiction, social media addiction) were the consequence of interactions between predisposing variables (e.g., neurobiological and psychological components), moderators (e.g., coping style and internet-related cognitive biases), and mediators (e.g., affective and cognitive responses to specific stimuli in combination with reduced executive functioning) $(66,67)$. In the early stages of behavioral addiction, negative or positive moods as internal triggers may be perceived, which result in affective (e.g., FoMO) and cognitive responses and increase attention to stimuli and urges to behave in specific ways (e.g., urge to use smartphone, play online gaming) $(67,68)$.

Some studies have reported that sleep disturbances are common among Chinese university students $(69,70)$. A recent meta-analysis examining sleep problems and internet addiction reported a significant odds ratio (OR) for sleep problems and a significant reduction in sleep duration among individuals addicted to the internet (71). Some studies have reported that sleep quality is positively associated with NA and negatively associated with PA $(72,73)$. Although, some scholars argue that the relationship between sleep quality and affect may be bidirectional (74-76), previous research has also shown that both positive and negative affect can mediate the impact of expressive suppression on sleep quality $(73,77)$. Another recent study showed that insomnia partially mediated a significant association of interpersonal stress and FoMO with 
mental health (78). Moreover, the relationship between negative affect and sleep quality may also be mediated by smartphone addiction (79).

Based on the I-PACE theory and previous studies, the aim of the present study was to carry out a multiple mediation analysis examining PA/NA to sleep quality, in which trait-FoMO/stateFoMO and smartphone addiction were the mediator variables. It was hypothesized that a) PA/NA, trait-FoMO/state-FoMO, and smartphone addiction would be associated with sleep quality; b) trait-FoMO and smartphone addiction would mediate the association between PA and sleep quality; c) state-FoMO and Smartphone addiction would mediate the association between PA and sleep quality; d) trait-FoMO and smartphone addiction would mediate the association between NA and sleep quality; and e) state-FoMO and smartphone addiction would mediate the association between NA and sleep quality (Figure 1).

\section{METHODS}

\section{Participants}

A cross-sectional study was carried out from October 2019 to November 2019. The survey was completed on the Wenjuanxing platform (www.wjx.cn). The participants comprised 1,258 students (from 17 to 25 years; mean age $=20.1$ years; $\mathrm{SD} \pm$ 1.6) by cluster convenience sampling from three universities in Jiangxi province and Liaoning province of China. However, 94 participants were excluded from the dataset owing to incomplete information. The final sample comprised 1,164 participants (656 females, 508 males) with a $92.5 \%$ response rate.

\section{Measures}

\section{Pittsburgh Sleep Quality Index (PSQI)}

Sleep quality was assessed using the Pittsburgh Sleep Quality Index (PSQI) (80), which assessed sleep disturbances during a 1month time period. The PSQI was translated into Chinese by Liu et al. (81). The instrument contains 19 items assessing seven components: subjective sleep quality, sleep latency, sleep duration, habitual sleep efficiency, sleep disturbances, use of sleep medication, and daytime dysfunction. The seven component scores are summed to produce a global PSQI score, where the total score ranges from 0 to 21 points ( 0 to 3 points for each component), with higher scores indicating worse sleep quality. The cut-off value for sleep disturbance is 7 (81). The Cronbach's alpha of the PSQI was 0.71 in the present study.

\section{International Positive and Negative Affect Scale Short-Form (I-PANAS-SF)}

Positive affect and negative affect were assessed using the International Positive and Negative Affect Scale Short-Form (IPANAS-SF) (82). The I-PANAS-SF comprises 10 items originating from the Positive and Negative Affect Schedule (PANAS) (61), and was translated into Chinese by Huang, Yang and Ji (83). NA and PA have five items respectively answered on a 5-point scale from 1 ("not at all") to 5 ("extremely"). A higher NA total score indicated more negative affect or the extent to which the individual feels aversive mood states and general distress, whereas a higher PA total score indicates more positive affect or the extent to which the individual feels enthusiastic, active, and alert. The Cronbach's alpha of the I-PANAS-SF was 0.72 , for PA was 0.71 , and for NA was 0.81 in the present study.

\section{Chinese Trait-State Fear of Missing Out Scale (T-SFoMOSC)}

The 12-item Trait-State Fear of Missing Out Scale (T-SFoMOS) was developed by Wegmann et al. (4) and assesses fear of missing out across two domains (i.e., trait-FoMO and state-FoMO). The first five items reflect trait-FoMO, whereas the remaining seven items are state-FoMO. Each item is rated on a 5-point Likert scale from 1 ("totally disagree") to 5 ("totally agree"). Higher total scores represent a higher level of FoMO. The Cronbach's alpha value of the trait-FoMO and state-FoMO were 0.82 and 0.81 , respectively. In the present study, using the T-SFoMOSC, the Cronbach's alpha for the total scale was $0.82,0.78$ for the traitFoMO, and 0.81 for state-FoMO.

\section{Mobile Phone Addiction Index (MPAl)}

Smartphone addiction was assessed using the Mobile Phone Addiction Index (MPAI) (84), which was translated into Chinese (85) and is used widely in Chinese contexts $(86,87)$. The MPAI contains 17 items assessing four domains: inability to control craving, feeling anxious and lost, withdrawal/escape, and productivity loss. Each item is responded to from 1 ("not at all") to 5 ("always"). Final scores were summed and higher total scores reflect higher levels of smartphone addiction. The Cronbach's alpha of the MPAI was 0.86 in the present study.

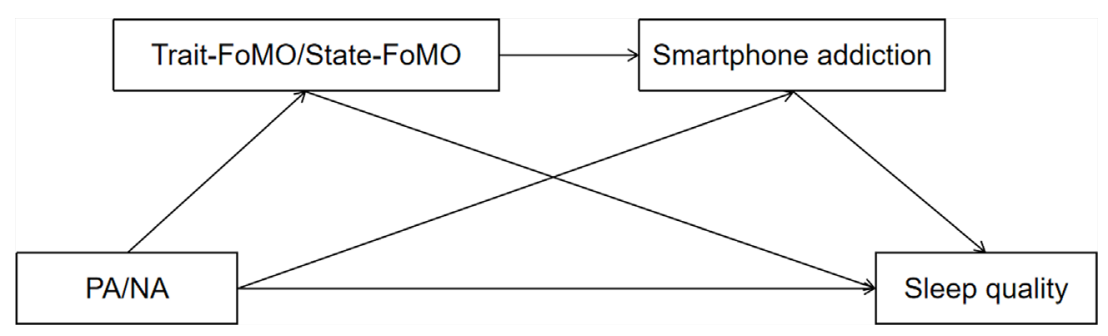

FIGURE 1 | The proposed series multiple mediation model. 


\section{Procedure}

The survey was conducted in three universities [Gannan Medical University (542 participants), Jiangxi University of Science and Technology (418 participants), and Jinzhou Medical University (298 participants)] in the two provinces of China from October 2019 to November 2019. Participants received a detailed explanation of the study' purpose and completed the survey, and participants received course credits in mental health education classes. Four self-report scales including the PQSI, the I-PANAS-SF, the T-SFoMOS, and the MPAI were completed in approximately $10 \mathrm{~min}$.

\section{Statistical Analysis}

SPSS 20 was used for the present study analysis. The skewness and kurtosis levels were examined for data distribution (with a skewness cut-off of 2.0 and kurtosis cut-off of 7.0) (88). Descriptive analysis of the sample' characteristics was conducted by means, standard deviations, and frequency analysis. A chi-square test was utilized for analyzing the gender difference in sleep disturbance. Pearson correlation tests were applied among all variables. The series of multiple mediation models of positive/negative affect on sleep quality via traitFoMO/state-FoMO and smartphone addiction were tested using Model 6 of Hayes's PROCESS tool (89).

\section{Ethics}

The study was approved by the Ethics Committee of Gannan Medical University, and was carried out in accordance with the requisite ethical standards (e.g., the Helsinki declaration). Written informed consent was obtained from all participants.

\section{RESULTS}

\section{Descriptive Statistics and Correlation Analyses}

Descriptive statistics are displayed in Table 1. Data were regarded as normal distribution due to the maximum values of skewness $(<2)$ and kurtosis $(<7)$. PA was significantly positively associated with state-FoMO $(r=0.09, p<.01)$, but significantly negatively associated with smartphone addiction $(r=-0.06, p<.05)$ and poor sleep quality $(r=-0.09, p<.01)$. PA was not significantly associated with the total scores of FoMO $(r=0.05, p=0.110)$ and trait-FoMO $(r=-0.02, p=$ $0.509)$. NA was significantly positively associated with trait-FoMO
( $r=0.26, p<.01)$, state-FoMO $(r=0.16, p<.01)$, smartphone addiction $(r=0.31, p<.01)$, and poor sleep quality $(r=0.42, p<.01)$. Trait-FoMO was significantly positively associated with smartphone addiction $(r=0.33, p<.01)$ and poor sleep quality $(r=0.23, p<.01)$. State-FoMO was significantly positively associated with smartphone addiction $(r=0.42, p<.01)$ and poor sleep quality $(r=0.19, p<.01)$. Smartphone addiction was also significantly positively associated with poor sleep quality $(r=0.32, p<.01)$.

\section{The Prevalence of Sleep Disturbance}

Based on 7 as the threshold value for the PQSI (81), of the 1,164 participants, $978(84.02 \%)$ reported normal sleep quality and 186 (15.98\%) reported sleep disturbance. The numbers of males (18.38\%, male 506) and females (14.13\%, female 658) with sleep disturbance were both 93 . There was no significant difference between gender $\left(\chi^{2}=3.53, p=0.06\right)$.

\section{Testing of the Mediation Effects From PA to Sleep Quality}

The series multiple mediation effects of PA on sleep quality via trait-FoMO/state-FoMO and smartphone addiction were tested using Model 6 of Hayes' PROCESS tool. Gender and age were regarded as control variables in the present study. As shown in Table 2, the total mediation effects of PA on sleep quality via trait-FoMO and smartphone addiction $(\beta=-0.018,95 \% \mathrm{CI}$ : $-0.043,0.006)$ as well as state-FoMO and smartphone addiction $(\beta=-0.009,95 \% \mathrm{CI}:-0.033,0.014)$ were both non-significant, whereas the direct effects of PA on sleep quality ( $\beta=-0.062,95 \%$ CI: $-0.114,-0.010 ; \beta=-0.070,95 \% \mathrm{CI}:-0.122,-0.018)$ were both significant. In the serial mediation model of trait-FoMO and smartphone addiction, the relationship between PA and poor sleep quality was not mediated by trait-FoMO $(\beta=-0.003,95 \%$ CI: $-0.012,0.006)$ or smartphone addiction $(\beta=-0.014,95 \% \mathrm{CI}$ : $-0.032,0.003)$. However, in the serial mediation model of stateFoMO and smartphone addiction, the relationship between PA and poor sleep quality was mediated by smartphone addiction ( $\beta=-0.024,95 \% \mathrm{CI}:-0.042,-0.007)$, but not state-FoMO $(\beta=$ 0.006, 95\%CI: $0.000,0.015)$.

\section{Testing of the Mediation Effects From NA to Sleep Quality via Trait-FoMO and Smartphone Addiction}

The serial multiple mediation effects of NA on sleep quality via trait-FoMO/state-FoMO and smartphone addiction were also

TABLE 1 | Descriptive statistics and correlation analysis of the study variables.

\begin{tabular}{|c|c|c|c|c|c|c|c|c|c|c|c|c|}
\hline & & $M$ & $S D$ & Skewness & Kurtosis & 1 & 2 & 3 & 4 & 5 & 6 & 7 \\
\hline 1. & Sleep quality & 5.26 & 2.29 & 0.279 & -0.051 & 1.00 & & & & & & \\
\hline 2. & Positive affect & 14.12 & 3.13 & -0.206 & 0.504 & $-0.09^{\star \star}$ & 1.00 & & & & & \\
\hline 3. & Negative affect & 10.69 & 3.37 & 0.389 & -0.176 & $0.42^{\star \star}$ & $0.07^{\star}$ & 1.00 & & & & \\
\hline 4. & FoMO & 29.07 & 6.95 & -0.160 & 0.151 & $0.25^{\star \star}$ & 0.05 & $0.24^{\star \star}$ & 1.00 & & & \\
\hline 5. & Trait-FoMO & 12.19 & 3.63 & 0.008 & -0.170 & $0.23^{\star \star}$ & -0.02 & $0.26^{\star \star}$ & $0.79^{\star \star}$ & 1.00 & & \\
\hline 6 & State-FoMO & 16.88 & 4.63 & 0.121 & -0.007 & $0.19^{\star \star}$ & $0.09^{\star \star}$ & $0.16^{\star \star}$ & $0.88^{\star \star}$ & $0.41^{\star \star}$ & 1.00 & \\
\hline 7 & Smartphone addiction & 42.09 & 10.24 & 0.052 & -0.116 & $0.32^{\star \star}$ & $-0.06^{\star}$ & $0.31^{\star \star}$ & $0.45^{\star \star}$ & $0.33^{\star \star}$ & $0.42^{\star \star}$ & 1.00 \\
\hline
\end{tabular}

$* * p<.01, * p<.05$. 
TABLE 2 | Total effect, direct effect, and mediation effects of PA/NA on sleep quality via trait-FoMO/state-FoMO and smartphone addiction.

\begin{tabular}{|c|c|c|c|c|c|c|c|}
\hline Path (PA $\rightarrow$ trait-FoMO) & B & SE & $95 \% \mathrm{Cl}$ & Path (PA $\rightarrow$ state-FoMO) & B & SE & $95 \% \mathrm{Cl}$ \\
\hline Total effect & -0.079 & 0.028 & $-0.134,-0.024$ & Total effect & -0.079 & 0.028 & $-0.134,-0.024$ \\
\hline Direct effect & -0.062 & 0.026 & $-0.114,-0.010$ & Direct effect & -0.070 & 0.027 & $-0.122,-0.018$ \\
\hline Total mediation effect & -0.018 & 0.012 & $-0.043,0.006$ & Total mediation effect & -0.009 & 0.012 & $-0.033,0.014$ \\
\hline Ind1 & -0.003 & 0.004 & $-0.012,0.006$ & Ind1 & 0.006 & 0.004 & $0.000,0.015$ \\
\hline Ind2 & -0.014 & 0.009 & $-0.032,0.003$ & Ind2 & -0.024 & 0.009 & $-0.042,-0.008$ \\
\hline Ind3 & -0.002 & 0.003 & $-0.007,0.004$ & Ind3 & 0.008 & 0.004 & $0.000,0.017$ \\
\hline Path (NA $\rightarrow$ trait-FoMO) & $B$ & SE & $95 \% \mathrm{Cl}$ & Path (NA $\rightarrow$ state-FoMO) & $\mathrm{B}$ & SE & $95 \% \mathrm{Cl}$ \\
\hline Total effect & 0.414 & 0.027 & $0.362,0.466$ & Total effect & 0.414 & 0.027 & $0.362,0.466$ \\
\hline Direct effect & 0.336 & 0.028 & $0.282,0.391$ & Direct effect & 0.348 & 0.027 & $0.295,0.402$ \\
\hline Total mediation effect & 0.078 & 0.012 & $0.055,0.103$ & Total mediation effect & 0.066 & 0.011 & $0.046,0.089$ \\
\hline Ind1 & 0.021 & 0.008 & $0.006,0.037$ & Ind1 & 0.012 & 0.005 & $0.002,0.024$ \\
\hline Ind2 & 0.045 & 0.009 & $0.028,0.063$ & Ind2 & 0.044 & 0.009 & $0.027,0.062$ \\
\hline Ind3 & 0.013 & 0.003 & $0.007,0.019$ & Ind3 & 0.011 & 0.003 & $0.006,0.017$ \\
\hline C1 & -0.024 & 0.013 & $-0.050,0.002$ & C1 & -0.032 & 0.012 & $-0.056,-0.009$ \\
\hline $\mathrm{C} 2$ & 0.008 & 0.009 & $-0.009,0.026$ & $\mathrm{C} 2$ & 0.001 & 0.006 & $-0.011,0.014$ \\
\hline C3 & 0.032 & 0.008 & $0.017,0.049$ & C3 & 0.033 & 0.008 & $0.018,0.049$ \\
\hline Effect ratio (\%) & 19.1 & & & Effect ratio (\%) & 16.2 & & \\
\hline
\end{tabular}

Confidence intervals for effects are bias corrected based on 5,000 bootstrap samples. a1. PA/NA to Trait-FoMO/State-FoMO, a2. PA/NA to smartphone addiction, b1. Trait-FoMO/StateFoMO to sleep quality, b2. Smartphone addiction to sleep quality, d1. Trait-FoMO/State-FoMO to smartphone addiction. Ind1 = PA/NA $\rightarrow$ Trait-FoMO/State-FoMO $\rightarrow$ Sleep quality, Ind2 = $P A / N A \rightarrow$ Smartphone addiction $\rightarrow$ Sleep quality, Ind3 =PA/NA $\rightarrow$ Trait-FoMO/State-FoMO $\rightarrow$ Smartphone addiction $\rightarrow$ Sleep quality. Cl =Ind1 minus Ind2, C2 =Ind1 minus Ind3, C3 =Ind2 minus Ind3. Effect ratio = Total mediation effect/Total effect.

Bold values are highlighted to show where the $95 \%$ confidence interval (Cl) contains zero, then the effect will not be significant at the 0.05 level..

examined and gender and age were also regarded as control variables. As Figure 2 shows, NA was positively associated with trait-FoMO $(\beta=0.28, t=9.21, p<.001)$ and smartphone addiction $(\beta=0.26, t=8.74, p<.001)$. Trait-FoMO was positively associated smartphone addiction $(\beta=0.26, t=9.41$, $p<.001)$ and poor sleep quality $(\beta=0.07, t=2.84, p<.01)$. Smartphone addiction was positively associated with poor sleep quality $(\beta=0.17, t=6.47, p<.001)$. In addition, the total indirect effect of NA and sleep quality via Trait-FoMO and smartphone addiction was significant $(\beta=0.078,95 \% \mathrm{CI}: 0.055,0.103)$, as well as the direct effect $(\beta=0.336,95 \% \mathrm{CI}: 0.282,0.391)$ and total effect $(\beta=0.414,95 \% \mathrm{CI}: 0.362,0.466)$. Three indirect paths from NA to sleep quality via Trait-FoMO ( $\beta=0.021,95 \%$ CI: 0.006 , $0.037)$, smartphone addiction $(\beta=0.045,95 \% \mathrm{CI}: 0.028,0.063)$, and Trait-FoMO and smartphone addiction $(\beta=0.013,95 \% \mathrm{CI}$ : $0.007,0.019)$, were significant respectively. Moreover, differences in the three paths were tested using Model 6 of the PROCESS tool. A significant difference $(\beta=0.032,95 \% \mathrm{CI}$ : $0.017,0.049)$ between Path 2 (NA on sleep quality via smartphone addiction) and Path 3 (NA on sleep quality via trait-FoMO and smartphone addiction) was found (Table 2 ).

\section{Testing of the Mediation Effects From NA to Sleep Quality via State-FoMO and Smartphone Addiction}

NA was positively associated with state-FoMO $(\beta=0.17, t=5.55, p$ $<.001)$ and smartphone addiction $(\beta=0.26, t=9.65, p<.001)$. StateFoMO was positively associated with smartphone addiction $(\beta=$ $0.38, t=14.98, p<.001)$ and poor sleep quality $(\beta=0.07, t=2.54, p$ $<.05)$. Smartphone addiction was positively associated with poor sleep quality $(\beta=0.17, t=5.84, p<.001)$ (Figure 3). In addition, the total indirect effect from NA to sleep quality via state-FoMO and smartphone addiction was significant ( $\beta=0.066,95 \% \mathrm{CI}: 0.046$, 0.089 ), as well as the direct effect ( $\beta=0.348,95 \% \mathrm{CI}: 0.295,0.402)$ and total effect $(\beta=0.414,95 \% \mathrm{CI}: 0.362,0.466)$. Three indirect paths from NA to sleep quality via state-FoMO $(\beta=0.012,95 \% \mathrm{CI}$ :

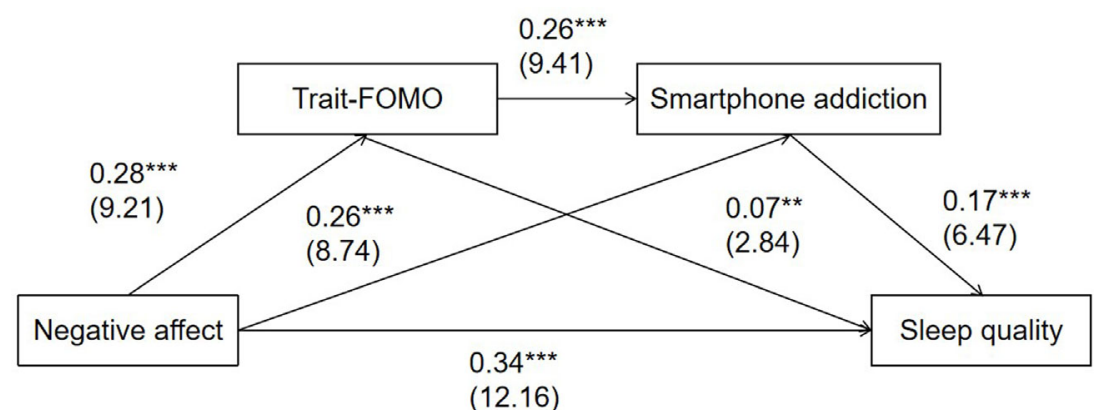

FIGURE 2 | The serial multiple mediation model of fear of missing out and smartphone addiction on negative affect and sleep quality ( $\mathrm{n}=1164)$. Coefficients are standardized and $t$-statistics are in parentheses. ${ }^{\star \star *} p<.001 ;{ }^{\star \star} p<.01$. 


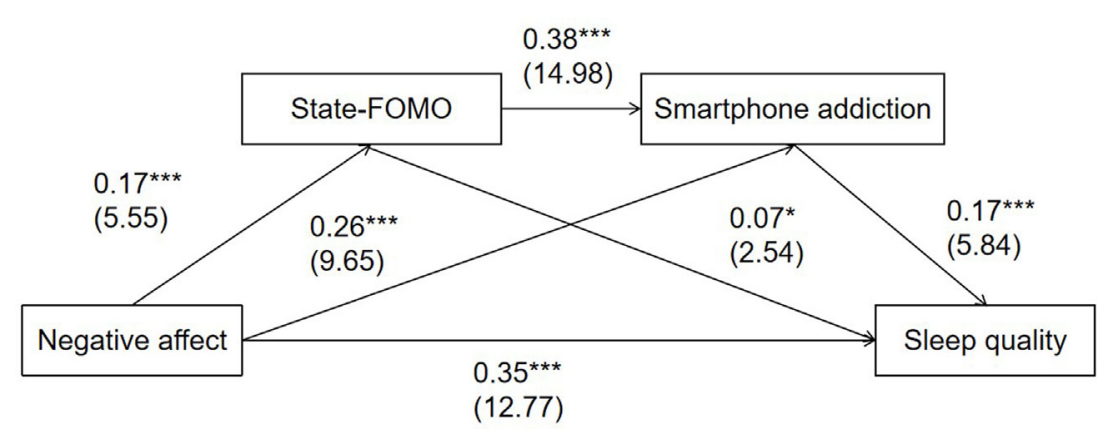

FIGURE 3 | The serial multiple mediation model of fear of missing out and smartphone addiction on negative affect and sleep quality ( $\mathrm{n}=1164)$. Coefficients are standardized and $t$-statistics are in parentheses. ${ }^{\star * *} p<.001 ;{ }^{*} p<.05$.

$0.002,0.024)$, smartphone addiction $(\beta=0.044,95 \% \mathrm{CI}: 0.027$, $0.062)$, and state-FoMO and smartphone addiction $(\beta=0.011$, $95 \%$ CI: $0.006,0.017)$ were all significant. Moreover, differences in the three paths were tested using Model 6 of the PROCESS tool. Significant differences between Path 1 (NA on sleep quality via state-FoMO) and Path 2 (NA on sleep quality via smartphone addiction) $(\beta=-0.032,95 \% \mathrm{CI}:-0.056,-0.009)$, as well as Path 2 (NA on sleep quality via smartphone addiction) and Path 3 (NA on sleep quality via state-FoMO and smartphone addiction) $(\beta=0.033,95 \%$ CI: $0.018,0.049)$ were found. The proportion of total effect from NA to sleep quality via trait-FoMO and smartphone addiction was $19.1 \%$ and via state-FoMO and smartphone addiction was $16.2 \%$.

\section{DISCUSSION}

The present study reported the prevalence of sleep disturbance and the mediation effects of positive and negative affect on sleep quality via trait-FoMO/state-FoMO and smartphone addiction among Chinese university students. The prevalence of sleep disturbance was $15.98 \%$, which finding is similar to previous findings among Chinese samples (13.93\%-15.8\%) $(29,69,70)$.

NA was positively associated with state-FoMO and trait-FoMO, whereas there was a positive correlation between PA and stateFoMO [e.g., "When I have a good time it is important for me to share the details online (e.g. updating status)"]. This may be because individuals with high state-FoMO like to share their enjoyment, interests, achievements with others anywhere at any time. As Przybylski et al. noted, individuals who experience high FoMO have mixed feelings [i.e., positive affect (excitement and joy) and negative affect (fear and anxiety)] when they use social media (1).

The correlation coefficient between FoMO and smartphone addiction $(r=0.42)$ was similar to study samples from other countries (ranging from 0.40 to 0.60$)(11,18,90-92)$. This indicates that the impact of FoMO and excessive smartphone use are arguably ubiquitous in the global context (93-97).

NA was significantly positively associated with FoMO and smartphone addiction, which is consistent with other findings $(18,98)$. Elhai et al. reported that NA (i.e., depression and anxiety) may impact on smartphone addiction via FoMO (91), which was also consistent with the finding's here. However, depression and interpersonal sensitivity on internet-communication disorder (ICD) via avoidance expectancies and state-FoMO have been found, but not for trait-FoMO (4). This perhaps indicates FoMO is a more complex construct. According to self-determination theory (SDT) (99), FoMO is considered as "a phenomenon of selfregulatory limbo arising from a situational or chronic deficit in psychological need satisfaction" (1). Consequently, FoMO was described as "a relatively stable individual characteristic, representing the general fear of a person of missing out on something" (i.e., trait-FoMO) (4). On the contrary, state-FoMO is considered important in the context of utilizing social media, where messages are updated and exchanged. State-FoMO even may increase general trait-FoMO (4). Based on the Brand et al.'s theory of specific internet addiction, a person's core characteristics (e.g., depression and social anxiety) and personality (e.g., stress vulnerability, self-esteem, self-efficacy) predict specific cognitions, consequently causing different types of internet addiction (e.g., smartphone addiction and internet-communication addiction) $(100,101)$. In terms of interaction in the person-affect-cognitionexecution (I-PACE) model (64), State-FoMO may represent a specific cognition, which mediates individual core characteristics (NA) and smartphone addiction, whereas trait-FoMO being a dispositional trait, may develop state-FoMO and specific internet cognition (4).

Results also showed that PA and NA both predicted sleep quality, and that NA had a more prominent influence than PA. These results suggest that regulation of NA for sleep disturbance therapy may be more successful than improvement of PA (73). Therefore, treatments targeting a reduction of NA may decrease insomnia symptoms and improve sleep quality (77). The mediation effects of NA on sleep quality via trait-FoMO/stateFoMO and smartphone addiction were statistically significant. However, the total indirect effects of PA on sleep quality via traitFoMO/state-FoMO and smartphone addiction were not found. Moreover, smartphone addiction had higher mediation effect from NA to sleep quality. The relationship between NA, smartphone addiction, and sleep quality was also consistent with findings from a previous study (79). 
Smartphone use may be pleasurable and exciting in the early stage when individuals communicate with others or engage in other activities (i.e., individuals experience positive affect). However, for a small minority of individuals, excessive smartphone use can trigger greater negative affect, such as irritable, anxiety, and depression, which may lead to smartphone addiction, and disturb individuals' sleep quality. Some studies have reported that negative events impacting on sleep quality mainly included bad dormitory conditions (e.g., noisy roommates, snoring, gaming, lighting, mosquitos), interpersonal conflict, academic pressure, freshmen maladjustment, as well as romantic relationship problems $)(102,103)$. Due to specific characteristics of smartphones (e.g., the many different types of applications), smartphones can be considered as tools that provide selfcomfort and satisfy basic need of communication with others in a timely way (i.e., individuals, especially females prefer texting, blogging and chatting via smartphone) (104-106). Consequently, all kinds of messages from Chinese SNSs such as WeChat and QQ (e.g., different groups comprising class, grade, students' union, different courses, etc.) can seriously influence their academic performance and daily lives among Chinese university students. Therefore, one possible explanation is that NA (triggered by negative events and all kinds of stress) may increase the level of FoMO, and leads to students constantly check their smartphones (so as not to miss out on what they perceive to be important information) which among some individuals may give rise to smartphone addiction, and subsequently deteriorating sleep quality. The mediation effect of FoMO from NA to sleep quality appears to be weaker than smartphone addiction. These finding suggest that FoMO is closely associated with social media use, whereas smartphone addiction may be related to more specific activities (e.g., smartphone gaming addiction, smartphone shopping addiction, smartphone gambling addiction, etc.).

FoMO and smartphone addiction may mediate the relationship between negative affect and sleep quality. The pressures from school, college or university may prevent faceto-face social activity but being bombarded with excessive information via smartphone, which could lead to greater negative affect and affect both FoMO and smartphone addiction, subsequently leading students to have poorer sleep. However, several limitations are present in the present study. First, all data were self-report which may result in some biases (e.g., social desirability and memory recall). The cross-sectional study from three universities was non-representative, and is unable to explain any causal relationships between the variables tested. Future studies should be performed using more representative samples and longitudinal designs to determine if there are causal relationships between the variables FoMO, smartphone addiction, positive and negative affect, and sleep quality. Owing to gender and age as control variables in the present study, gender differences were not examined and there may be differences in relation to smartphone addiction as well as the relationship between affect and smartphone addiction. Demographic variables may potentially impact mediation effect (e.g., gender and age). Therefore such variables should be examined in future research. Second, further research is required to more deeply explore the characteristics of trait-FoMO and state-FoMO (e.g., studies evaluating the difference between trait-FoMO and stateFoMO as mediators). Third, further research is necessary to explain the specific positive affect and negative affect factors (e.g., alert, anxiety, fear) responsible for the relationships studied here.

Overall, the results demonstrate the mediation effects of traitFoMO/state-FoMO and smartphone addiction between negative affect and sleep quality. More specifically, smartphone addiction had higher effect size than the role of FoMO. Based on the findings, negative affect on sleep quality may be mediated via smartphone addiction and FoMO among Chinese university students.

\section{DATA AVAILABILITY STATEMENT}

The raw data supporting the conclusions of this article will be made available by the authors, without undue reservation.

\section{ETHICS STATEMENT}

The studies involving human participants were reviewed and approved by the Ethics Committee of Gannan Medical University. Written informed consent to participate in this study was provided by the participants' legal guardian/next of kin.

\section{AUTHOR CONTRIBUTIONS}

Conceived and designed the experiments: LL and ZN. Performed the experiments: LL and ZN. Analyzed the data: LL and MG. Contributed reagents/materials/analysis tools: SM. Wrote the paper: LL and ZN. Edited and contributed to the revised paper: MG.

\section{FUNDING}

The Science Education Program Project "Thirteenth FiveYear Plan" of Jiangxi Province 2020GX184, Doctor start-up fund of Gannan Medical University QD201819, Key project of Gannan Medical University ZD201838, The International Innovation Team of Jilin University 2019GJTD06.

\section{ACKNOWLEDGMENTS}

We would like to express our gratitude to Wenying Wang and Shuli $\mathrm{Xu}$ for their assistance in this study.

This manuscript "Fear of missing out (FoMO) and gaming disorder among Chinese university students: Impulsivity and game time as mediators" has been released as a pre-print at (Issues in Mental Health Nursing), (doi: 10.21203/rs.3.rs-25628/v1). 


\section{REFERENCES}

1. Przybylski AK, Murayama K, DeHaan CR. \& Gladwell V. Motivational, emotional, and behavioral correlates of fear of missing out. Comput Hum Behav (2013) 29(4):1841-8. doi: 10.1016/j.chb.2013.02.014

2. Alt D. Students' social media engagement and fear of missing out (FoMO) in a diverse classroom. J Computing Higher Educ (2017) 29(2):388-410. doi: 10.1007/s12528-017-9149-x

3. Xinli001. How to say goodbye to the fear of missing out. China: Guangzhou Renxin Network Technology Co. LTD. (2016). Retrieved January, 27, 2020, from:http://www.xinli001.com/info/100001714/

4. Wegmann E, Oberst U, Stodt B, Brand M. Online-specific fear of missing out and Internet-use expectancies contribute to symptoms of internet communication disorder. Addictive Behav Rep (2017) 5:33-42. doi: 10.1016/ j.abrep.2017.04.001

5. Lai C, Altavilla D, Ronconi A, Aceto P. Fear of missing out (FOMO) is associated with activation of the right middle temporal gyrus during inclusion social cue. Comput Hum Behav (2016) 61:516-21. doi: 10.1016/ j.chb.2016.03.072

6. Buglass SL, Binder JF, Betts LR, Underwood JDM. Motivators of online vulnerability: The impact of social network site use and FOMO. Comput Hum Behav (2017) 66:248-55. doi: 10.1016/j.chb.2016.09.055

7. Błachnio A, Przepiórka A. Facebook intrusion, fear of missing out, narcissism, and life satisfaction: A cross-sectional study. Psychiatry Res (2018) 259:514-9. doi: 10.1016/j.psychres.2017.11.012

8. Primack BA, Shensa A, Escobar-Viera CG, Barrett EL, Sidani JE, Colditz JB, et al. Use of multiple social media platforms and symptoms of depression and anxiety: A nationally-representative study among U.S. young adults. Comput Hum Behav (2017) 69:1-9. doi: 10.1016/j.chb.2016.11.013

9. Andreassen CS, Billieux J, Griffiths MD, Kuss DJ, Demetrovics Z, Mazzoni E, et al. The relationship between addictive use of social media and video games and symptoms of psychiatric disorders: A large-scale cross-sectional study. Psychol Addictive Behav (2016) 30(2):252-62. doi: 10.1037/adb0000160

10. Beyens I, Frison E, Eggermont S. “I don't want to miss a thing": Adolescents' fear of missing out and its relationship to adolescents' social needs, Facebook use, and Facebook related stress. Comput Hum Behav (2016) 64:1-8. doi: 10.1016/j.chb.2016.05.083

11. Oberst U, Wegmann E, Stodt B, Brand M, Chamarro A. Negative consequences from heavy social networking in adolescents: The mediating role of fear of missing out. J Adolescence (2017) 55:51-60. doi: 10.1016/ j.adolescence.2016.12.008

12. Xie X, Wang Y, Wang P, Zhao F, Lei L. Basic psychological needs satisfaction and fear of missing out: Friend support moderated the mediating effect of individual relative deprivation. Psychiatry Res (2018) 268:223-8. doi: 10.1016/j.psychres.2018.07.025

13. Alt D. Students' wellbeing, fear of missing out, and social media engagement for leisure in higher education learning environments. Curr Psychol (2018) 37(1):128-38. doi: 10.1007/s12144-016-9496-1

14. Tresnawati FR. Hubungan antara the big five personality traits dengan fear of missing out about social media pada mahasiswa. Intuisi: J Ilmiah Psikologi (2016) 8(3):179-85. doi: 10.15294/intuisi.v8i3.8661

15. Stead H, Bibby PA. Personality, fear of missing out and problematic internet use and their relationship to subjective well-being. Comput Hum Behav (2017) 76:534-40. doi: 10.1016/j.chb.2017.08.016

16. Alt D, Boniel-Nissim M. Using multidimensional scaling and PLS-SEM to assess the relationships between personality traits, problematic internet use, and fear of missing out. Behav Inf Technol (2018) 37(12):1264-76. doi: 10.1080/0144929X.2018.1502353

17. Blackwell D, Leaman C, Tramposch R, Osborne C, Liss M. Extraversion, neuroticism, attachment style and fear of missing out as predictors of social media use and addiction. Pers Individ Dif (2017) 116:69-72. doi: 10.1016/ j.paid.2017.04.039

18. Wolniewicz CA, Tiamiyu MF, Weeks JW, Elhai JD. Problematic smartphone use and relations with negative affect, fear of missing out, and fear of negative and positive evaluation. Psychiatry Res (2018) 262:618-23. doi: 10.1016/ j.psychres.2017.09.058

19. Pontes HM, Taylor M, Stavropoulos V. Beyond "Facebook addiction": The role of cognitive-related factors and psychiatric distress in social networking site addiction. Cyberpsychology Behavior Soc Networking (2018) 21(4):240-7. doi: 10.1089/cyber.2017.0609

20. Dempsey AE, O’Brien KD, Tiamiyu MF, Elhai JD. Fear of missing out (FoMO) and rumination mediate relations between social anxiety and problematic Facebook use. Addictive Behav Rep (2019) 9:100150. doi: 10.1016/j.abrep.2018.100150

21. Liu C, Ma J. Social support through online social networking sites and addiction among college students: The mediating roles of fear of missing out and problematic smartphone use. Curr Psychol (2018) 37:1-8. doi: 10.1007/ s12144-018-0075-5

22. Tunc-Aksan A, Akbay SE. Smartphone addiction, fear of missing out, and perceived competence as predictors of social media addiction of adolescents. Eur J Educ Res (2019) 8(2):559-66. doi: 10.12973/eu-jer.8.2.559

23. Li L, Griffiths MD, Mei SL, Niu ZM. Fear of missing out (FoMO) and gaming disorder among Chinese university students: Impulsivity and game time as mediators. Issues Ment Health Nurs (2020). doi: 10.21203/rs.3.rs-25628/v1. Advance online publication.

24. Balta S, Emirtekin E, Kircaburun K, Griffiths MD. Neuroticism, trait fear of missing out, and phubbing: The mediating role of state fear of missing out and problematic Instagram use. Int J Ment Health Addict (2020) 18:628-39. doi: 10.1007/s11469-018-9959-8

25. Alt D. College students' academic motivation, media engagement and fear of missing out. Comput Hum Behav (2015) 49:111-9. doi: 10.1016/ j.chb.2015.02.057

26. Milyavskaya M, Saffran M, Hope N, Koestner R. Fear of missing out: prevalence, dynamics, and consequences of experiencing FOMO. Motivation Emotion (2018) 42(5):725-37. doi: 10.1007/s11031-018-9683-5

27. Gezgin DM. Relationship among smartphone addiction, age, lack of sleep, fear of missing out and social networking sites use among high school students. Cypriot J Educ Sci (2018) 13(2):409-21. doi: 10.18844/ cjes.v13i2.2938

28. Gezgin DM. Understanding patterns for smartphone addiction: Age, sleep duration, social network use and fear of missing out. Cypriot J Educ Sci (2018) 13(2):166-77. doi: 10.18844/cjes.v13i2.2938

29. China Internet Network Information Center (CNNIC). The 45th statistical report on internet development in China. China: China Internet Network Information Center (2020). Retrieved June 4, 2020. from: http://www.cnnic. net.cn/hlwfzyj/hlwxzbg/hlwtjbg/202004/P020200428596599037028.pdf

30. Li L, Mei SL, Niu ZM, Song YT. Loneliness and sleep quality in university students: mediator of smartphone addiction and moderator of gender. Chin J Clin Psychol (2016) 24(2):345-8. doi: 10.16128/j.cnki.1005-3611.2016.02.036

31. Kwon M, Kim DJ, Cho H, Yang S. The smartphone addiction scale: development and validation of a short version for adolescents. PLoS One (2013) 8(12):e83558. doi: 10.1371/journal.pone.0083558

32. Kumar VA, Chandrasekaran V, Brahadeeswari H. Prevalence of smartphone addiction and its effects on sleep quality: A cross-sectional study among medical students. Ind Psychiatry J (2019) 28(1):82-5. doi: 10.4103/ipj.ipj_56_19

33. Long J, Liu TQ, Liao YH, Qi C, He HY, Chen SB, et al. Prevalence and correlates of problematic smartphone use in a large random sample of Chinese undergraduates. BMC Psychiatry (2016) 16(1):408. doi: 10.1186/ s12888-016-1083-3

34. Griffiths MD. Technological addictions. Clin Psychol Forum (1995) 76:14-9.

35. Griffiths MD. Internet addiction: Does it really exist? In: Gackenbach J, editor. Psychology and the internet: Intrapersonal, interpersonal and transpersonal applications. New York: Academic Press (1998). p. 61-75.

36. Montag C, Bey K, Sha P, Li M, Chen YF, Liu WY, et al. Is it meaningful to distinguish between generalized and specific Internet addiction? Evidence from a cross-cultural study from Germany, Sweden, Taiwan and China. Asia-Pacific Psychiatry (2015) 7(1):20-6. doi: 10.1111/appy.12122

37. Chen IH, Strong C, Lin YC, Tsai MC, Leung H, Lin CY, et al. Time invariance of three ultra-brief internet-related instruments: Smartphone Application-Based Addiction Scale (SABAS), Bergen Social Media Addiction Scale (BSMAS), and the nine-item Internet Gaming Disorder Scale-Short Form (IGDS-SF9)(Study Part B). Addictive Behav (2020) 101:105960. doi: 10.1016/j.addbeh.2019.04.018

38. Billieux J. Problematic use of the mobile phone: a literature review and a pathways model. Curr Psychiatry Rev (2012) 8(4):299-307. doi: 10.2174/ 157340012803520522 
39. Jiang Q, Li Y, Shypenka V. Loneliness, Individualism, and Smartphone Addiction Among International Students in China. Cyberpsychology Behavior Soc Networking (2018) 21(11):711-8. doi: 10.1089/cyber.2018.0115

40. Matar Boumosleh J, Jaalouk D. Depression, anxiety, and smartphone addiction in university students- A cross sectional study. PLoS One (2017) 12(8):e0182239. doi: 10.1371/journal.pone.0182239

41. Park N, Lee H. Social implications of smartphone use: Korean college students' smartphone use and psychological well-being. Cyberpsychology Behavior Soc Networking (2012) 15(9):491-7. doi: 10.1089/cyber.2011.0580

42. Wu AM, Cheung VI, Ku L, Hung EP. Psychological risk factors of addiction to social networking sites among Chinese smartphone users. J Behav Addict (2013) 2(3):160-6. doi: 10.1556/JBA.2.2013.006

43. Li C, Liu D, Dong Y. Self-esteem and problematic smartphone use among adolescents: A moderated mediation model of depression and interpersonal trust. Front Psychol (2019) 10:2872. doi: 10.3389/fpsyg.2019.02872

44. Kim E, Cho I, Kim EJ. Structural equation model of smartphone addiction based on adult attachment theory: Mediating effects of loneliness and depression. Asian Nurs Res (2017) 11(2):92-7. doi: 10.1016/j.anr.2017. 05.002

45. Hussain Z, Griffiths MD, Sheffield D. An investigation into problematic smartphone use: The role of narcissism, anxiety, and personality factors. J Behav Addict (2017) 6(3):378-86. doi: 10.1556/2006.6.2017.052

46. Grant JE, Lust K, Chamberlain SR. Problematic smartphone use associated with greater alcohol consumption, mental health issues, poorer academic performance, and impulsivity. J Behav Addict (2019) 8(2):335-42. doi: 10.1556/2006.8.2019.32

47. Kim J, Hwang Y, Kang S, Kim M, Kim TS, Kim J, et al. Association between Exposure to Smartphones and Ocular Health in Adolescents. Ophthalmic Epidemiol (2016) 23(4):269-76. doi: 10.3109/09286586.2015.1136652

48. Nguyen-Phuoc DQ, Oviedo-Trespalacios O, Su DN, De Gruyter C, Nguyen T. Mobile phone use among car drivers and motorcycle riders: The effect of problematic mobile phone use, attitudes, beliefs and perceived risk. Accident Anal Prev (2020) 143:105592. doi: 10.1016/j.aap.2020.105592

49. Alsalameh AM, Harisi MJ, Alduayji MA, Almutham AA, Mahmood FM. Evaluating the relationship between smartphone addiction/overuse and musculoskeletal pain among medical students at Qassim University. J Family Med Primary Care (2019) 8(9):2953. doi: 10.4103/jfmpc. jfmpc_665_19

50. Yang SY, Chen MD, Huang YC, Lin CY, Chang JH. Association between smartphone use and musculoskeletal discomfort in adolescent students. J Community Health (2017) 42(3):423-30. doi: 10.1007/s10900-016-0271-x

51. Lee J, Seo K. The comparison of cervical repositioning errors according to smartphone addiction grades. J Phys Ther Sci (2014) 26(4):595-8. doi: 10.1589/jpts.26.595

52. Zirek E, Mustafaoglu R, Yasaci Z, Griffiths MD. A systematic review of musculoskeletal disorders related to mobile phone usage. Musculoskeletal Sci Pract (2020) 49:102196. doi: 10.1016/j.msksp.2020.102196

53. Chung JE, Choi SA, Kim KT, Yee J, Kim JH, Seong JW, et al. Smartphone addiction risk and daytime sleepiness in Korean adolescents. J Paediatrics Child Health (2018) 54(7):800-6. doi: 10.1111/jpc.13901

54. Demirci K, Akgönül M, Akpinar A. Relationship of smartphone use severity with sleep quality, depression, and anxiety in university students. J Behav Addict (2015) 4(2):85-92. doi: 10.1556/2006.4.2015.010

55. Kuss DJ, Griffiths MD. Social networking sites and addiction: Ten lessons learned. Int J Environ Res Public Health (2017) 14(3):311. doi: 10.3390/ ijerph 14030311

56. Sha P, Sariyska R, Riedl R, Lachmann B, Montag C. Linking internet communication and smartphone use disorder by taking a closer look at the Facebook and WhatsApp applications. Addictive Behav Rep (2019) 9:100148. doi: 10.1016/j.abrep.2018.100148

57. Lee AK, Lee H. Negative urgency mediates the relation between negative emotion and smartphone addiction. Korean J Stress Res (2019) 27(4):396403. doi: $10.17547 / \mathrm{kjsr}$.2019.27.4.396

58. Zajonc RB. Feeling and thinking. Preferences need no inferences. Am Psychol (1980) 35:151-75. doi: 10.1037/0003-066X.35.2.151

59. Diener E, Emmons RA. The independence of positive and negative affect. J Pers Soc Psychol (1984) 47:1105-17. doi: 10.1037/0022-3514.47.5.1105
60. Watson D, Tellegen A. Toward a consensual structure of mood. Psychol Bull (1985) 98(2):219-35. doi: 10.1037/0033-2909.98.2.219

61. Watson D, Clark LA, Tellegen A. Development and validation of brief measures of positive and negative affect: the PANAS scales. J Pers Soc Psychol (1988) 54(6):1063-70. doi: 10.1037/0022-3514.54.6.1063

62. Riordan BC, Cody L, Flett JA, Conner TS, Hunter J, Scarf D. The development of a single item FoMO (fear of missing out) scale. Curr Psychol (2018) 37:1-6. doi: 10.1007/s12144-018-9824-8

63. Shin D, Choi AR, Lee J, Chung SJ, Kim B, Park M, et al. The mediating effects of affect on associations between impulsivity or resilience and internet gaming disorder. J Clin Med (2019) 8(8):1102. doi: 10.3390/jcm8081102

64. Wang P, Wang X, Nie J, Zeng P, Liu K, Wang J, et al. Envy and problematic smartphone use: The mediating role of FOMO and the moderating role of student-student relationship. Pers Individ Dif (2019) 146:136-42. doi: 10.1016/j.paid.2019.04.013

65. Yin L, Wang P, Nie J, Guo J, Feng J, Lei L. Social networking sites addiction and FoMO: The mediating role of envy and the moderating role of need to belong. Curr Psychol (2019) 38:1-9. doi: 10.1007/s12144-019-00344-4

66. Brand M, Young KS, Laier C, Wölfling K, Potenza MN. Integrating psychological and neurobiological considerations regarding the development and maintenance of specific Internet-use disorders: An Interaction of Person-Affect-Cognition-Execution (I-PACE) model. Neurosci Biobehav Rev (2016) 71:252-66. doi: 10.1016/j.neubiorev. 2016.08.033

67. Brand M, Wegmann E, Stark R, Müller A, Wölfling K, Robbins TW, et al. The Interaction of Person-Affect-Cognition-Execution (I-PACE) model for addictive behaviors: Update, generalization to addictive behaviors beyond Internet-use disorders, and specification of the process character of addictive behaviors. Neurosci Biobehav Rev (2019) 104:1-10. doi: 10.1016/j.neubiorev. 2019.06.032

68. Starcke K, Antons S, Trotzke P, Brand M. Cue-reactivity in behavioral addictions: A meta-analysis and methodological considerations. J Behav Addict (2018) 7(2):227-38. doi: 10.1556/2006.7.2018.39

69. Liu XC, MQ T, Hu L, Wang AZ, Chen K, Zhao GF. Sleep quality and its correlates in college students. Chin Ment Health J (1995) 9(4):148-50. doi: 10.3321/j.issn:1000-6729.1995.04.003

70. Tong $\mathrm{P}, \mathrm{Wu} \mathrm{CH}$. Correlation between sleep quality and health condition of college students. China J Health Psychol (2010) 18(2):181-4. doi: 10.13342/ j.cnki.cjhp.2010.02.056

71. Alimoradi Z, Lin CY, Broström A, Bülow PH, Bajalan Z, Griffiths MD, et al. Internet addiction and sleep problems: A systematic review and metaanalysis. Sleep Med Rev (2019) 47:51-61. doi: 10.1016/j.smrv.2019.06.004

72. MacDonald S, Kormi-Nouri R. The affective personality, sleep, and autobiographical memories. J Positive Psychol (2013) 8(4):305-13. doi: 10.1080/17439760.2013.800904

73. Latif I, Hughes AT, Bendall RC. Positive and negative affect mediate the influences of a maladaptive emotion regulation strategy on sleep quality. Front Psychiatry (2019) 10:628. doi: 10.3389/fpsyt.2019.00628

74. Alvaro PK, Roberts RM, Harris JK. A systematic review assessing bidirectionality between sleep disturbances, anxiety, and depression. Sleep (2013) 36(7):1059-68. doi: 10.5665/sleep.2810

75. Steptoe A, O’Donnell K, Marmot M, Wardle J. Positive affect, psychological well-being, and good sleep. J Psychosomatic Res (2008) 64(4):409-15. doi: 10.1016/j.jpsychores.2007.11.008

76. van Zundert RM, van Roekel E, Engels RC, Scholte RH. Reciprocal associations between adolescents' night-time sleep and daytime affect and the role of gender and depressive symptoms. J Youth Adolescence (2015) 44 (2):556-69. doi: 10.1007/s10964-013-0009-3

77. Stewart JC, Rand KL, Hawkins MA, Stines JA. Associations of the shared and unique aspects of positive and negative emotional factors with sleep quality. Pers Individ Dif (2011) 50(5):609-14. doi: 10.1016/j.paid.2010.12.004

78. Adams SK, Murdock KK, Daly-Cano M, Rose M. Sleep in the social world of college students: Bridging interpersonal stress and fear of missing out with mental health. Behav Sci (2020) 10(2):54. doi: 10.3390/bs10020054

79. Li L, Mei SL, Niu ZM. Influences of smartphone addiction and negative affect on sleep quality among university students. Chin J Public Health (2016) 32(5):646-9. doi: 10.11847/zgggws2016-32-05-22 
80. Buysse DJ, Reynolds CF, Monk TH, Berman SR, Kupfer DJ. The Pittsburgh Sleep Quality Index: a new instrument for psychiatric practice and research. Psychiatry Res (1989) 28(2):193-213. doi: 10.1016/0165-1781(89)90047-4

81. Liu XC, MQ T, Hu L, Wang AZ, Wu HX. Reliability and validity of the Pittsburgh sleep quality index. Chin J Psychiatry (1996) 29(2):103-7. doi: 10.1007/BF02951625

82. Thompson ER. Development and validation of an internationally reliable short-form of the positive and negative affect schedule (PANAS). J CrossCultural Psychol (2007) 38(2):227-42. doi: 10.1177/0022022106297301

83. Huang L, Yang T, Li Z. Applicability of the Positive and Negative Affect Scale in Chinese. Chin Ment Health J (2003) 17(1):54-6. doi: 10.3321/j.issn:10006729.2003.01.018

84. Leung L. Linking psychological attributes to addiction and improper use of the mobile phone among adolescents in Hong Kong. J Children Media (2008) 2(2):93-113. doi: 10.1080/17482790802078565

85. Huang H, Niu LY, Zhou CY, Wu HM. Reliability and validity of mobile phone addiction index for Chinese college students. Chin J Clin Psychol (2014) 22(5):835-8. doi: 10.16128/j.cnki.1005-3611.2014.05.062

86. Zhao Y. Relationship between mobile phone dependence and perfectionism among college students in Nanjing: the mediating effect of social anxiety. Modern Preventive Med (2019) 46(12):2213-6. doi: CNKI:SUN:XDYF. 0.2019-12-024

87. Chen Y, Li C, Mu XL, Bie Z, Gu CH. The effect of subjective well-being on mobile phone addiction: the chain mediating effects of autonomous support and self-esteem. Chin J Special Educ (2019) 26(5):91-6. doi: 10.3969/ j.issn.1007-3728.2019.05.015

88. Curran PJ, West SG, Finch JF. The robustness of test statistics to nonnormality and specification error in confirmatory factor analysis. Psychol Methods (1996) 1(1):16-29. doi: 10.1037/1082-989X.1.1.16

89. Hayes AF. Introduction to mediation, moderation, and conditional process analysis: A regression-based approach. Guilford Press: New York (2013).

90. Elhai JD, Levine JC, Dvorak RD, Hall BJ. Fear of missing out, need for touch, anxiety and depression are related to problematic smartphone use. Comput Hum Behav (2016) 63:509-16. doi: 10.1016/j.chb.2016.05.079

91. Elhai JD, Levine JC, Alghraibeh AM, Alafnan A, Aldraiweesh A, Hall BJ. Fear of missing out: Testing relationships with negative affectivity, online social engagement, and problematic smartphone use. Comput Hum Behav (2018) 89:289-98. doi: 10.1016/j.chb.2018.08.020

92. Chotpitayasunondh V, Douglas KM. How "phubbing" becomes the norm: The antecedents and consequences of snubbing via smartphone. Comput Hum Behav (2016) 63:9-18. doi: 10.1016/j.chb.2016.05.018

93. Elhai JD, Yang H, Fang J, Bai Y, Hall BJ. Depression and anxiety symptoms are associated with problematic smartphone use severity in Chinese young adults: Fear of missing out as a mediator. Addictive Behav (2020) 101:105962. doi: 10.1016/j.addbeh.2019.04.020

94. Elhai JD, Yang H, Rozgonjuk D, Montag C. Using machine learning to model problematic smartphone use severity: the significant role of fear of missing out. Addictive Behav (2020) 103:106261. doi: 10.1016/j.addbeh. 2019.106261
95. Long J, Wang P, Liu S, Lei L. Materialism and adolescent problematic smartphone use: The mediating role of fear of missing out and the moderating role of narcissism. Curr Psychol (2019) 38:1-9. doi: 10.1007/ s12144-019-00526-0

96. Swar B, Hameed T. Fear of missing out, social media engagement, smartphone addiction and distraction: Moderating role of self-help mobile apps-based interventions in the youth. Biomed Eng Syst Technol (2017) 5:139-46. doi: 10.5220/0006166501390146

97. Wang J, Wang P, Yang X, Zhang GH, Wang XC, Zhao FQ, et al. Fear of missing out and procrastination as mediators between sensation seeking and adolescent smartphone addiction. Int J Ment Health Addict (2019) 17 (4):1049-62. doi: 10.1007/s11469-019-00106-0

98. Fuster H, Chamarro A, Oberst U. Fear of Missing Out, online social networking and mobile phone addiction: A latent profile approach. Aloma: Rev Psicologia Ciències l'Educacio i l'Esport (2017) 35(1):23-30.

99. Deci EL, Ryan RM. Intrinsic motivation and self-determination in human behavior. New York: Plenum (1985).

100. Brand M, Young KS, Laier C. Prefrontal control and Internet addiction: a theoretical model and review of neuropsychological and neuroimaging findings. Front Hum Neurosci (2014) 8:375. doi: 10.3389/fnhum.2014.00375

101. Wegmann E, Brand M. Internet-communication disorder: It's a matter of social aspects, coping, and Internet-use expectancies. Front Psychol (2016) 7:1747. doi: 10.3389/fpsyg.2016.01747

102. Pan JJ, Tan XD, Xie ZJ. Survey of sleep quality and relevant influencing factors in college students. China Trop Med (2007) 7(5):845-7. doi: 10.3969/ j.issn.1009-9727.2007.05.100

103. Qi DG, Liu R, Wu XQ, Pang J, Deng JB. Investigation on sleep quality of university students and its influential factors. Modern Preventive Med (2007) 134(5):875-7. doi: 10.3969/j.issn.1003-8507.2007.05.018

104. Billieux J, Van der Linden M, d'Acremont M, Ceschi G, Zermatten A. Does impulsivity relate to perceived dependence on and actual use of the mobile phone? Appl Cogn Psychol (2007) 21(4):527-37. doi: 10.1002/acp.1289

105. Vyjayanthi S, Makharam S, Afraz M, Gajrekar S. Gender differences in the prevalence and features of internet addiction among Indian college students. MedicaInnovatica (2014) 3(2):49-53.

106. Baloğlu M, Kozan HIÖ, Kesici Ş. Gender differences in and the relationships between social anxiety and problematic internet use: Canonical analysis. J Med Internet Res (2018) 20(1):e33. doi: 10.2196/jmir.8947

Conflict of Interest: The authors declare that the research was conducted in the absence of any commercial or financial relationships that could be construed as a potential conflict of interest.

Copyright $\odot 2020 \mathrm{Li}$, Griffiths, Mei and Niu. This is an open-access article distributed under the terms of the Creative Commons Attribution License (CC BY). The use, distribution or reproduction in other forums is permitted, provided the original author(s) and the copyright owner(s) are credited and that the original publication in this journal is cited, in accordance with accepted academic practice. No use, distribution or reproduction is permitted which does not comply with these terms. 